\title{
CEREMONIA DE GRADOS Y HOMENAJE AL PROFESOR JOSÉ IGNACIO HERNÁNDEZ CRUZ
}

Jorge Gómez Cusnir*

La ceremonia de graduación ocupa siempre un lugar de privilegio en la vida de las instituciones de educación, pues en ellas, con la entrega de los diplomas de grado en nombre de la República de Colombia y de su Ministerio de Educación, se certifica el cumplimiento de la misión institucional en la formación de talento humano. Al recibir el diploma que los acredita como especialistas, se certifica que han adquirido las competencias y destrezas para ejercer su profesión. Llevan ustedes la impronta de nuestras instituciones y la formación como profesionales íntegros para afrontar las dificultades de la actividad laboral.

Estamos en tiempos difíciles en los que la violencia golpea con sevicia los cimientos de nuestra democracia. Muchos de ustedes han sabido culminar sus estudios de posgrado, no sin dificultades, forzados por el deseo de progreso con el rigor académico y las obligaciones que demanda nuestro entorno social. Ustedes como médicos especialistas también serán protagonistas de un mundial que se juega todos los días, el de la salud. En este mundo se mueven grandes equipos empresariales, se intercambian opiniones con personas de diferentes nacionalidades, existe el turismo en salud como uno de los renglones más importantes de la economía global y se toman decisiones riesgosas sobre como alinear a un equipo de trabajo para competir en el mercado nacional e internacional. Ustedes son la nueva sangre que correrá por las venas del sistema de salud colombiano, de quienes dependerá la preservación de la vida en condiciones dignas.

Esta es una responsabilidad tan humana que debe llenarlos de humildad, de agradecimiento con la vida misma y sus semejantes, que les permitieron coronarse de laureles en una meta más; con ustedes demostramos

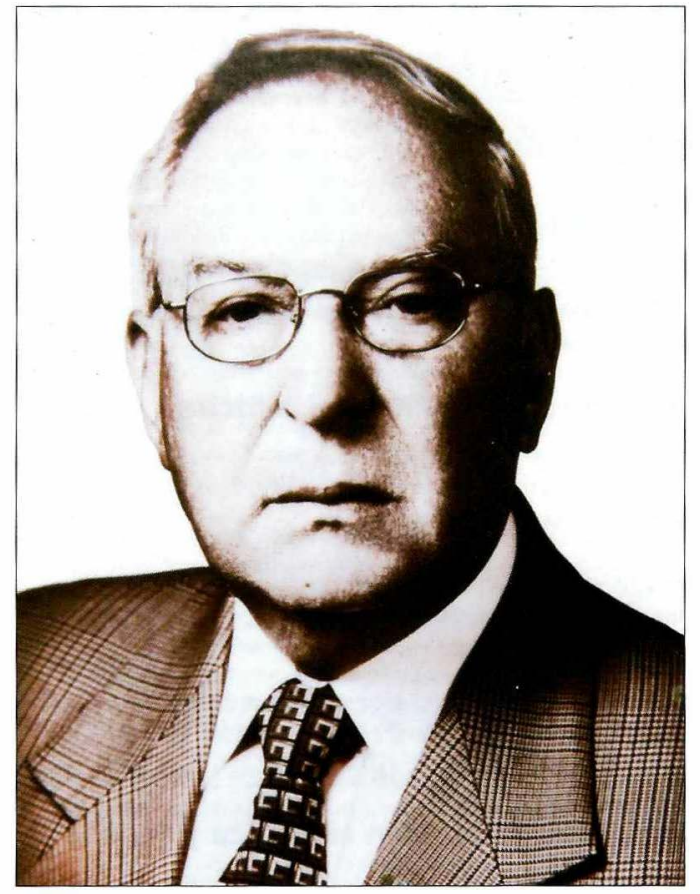

la victoria contra todos los obstáculos que encontramos en el camino. Hemos sorteado vicisitudes y cambios que bien podrían habernos vencido. Ustedes están aquí como los héroes gladiadores que luego de vencer en la arena a todo tipo de bestias, levantan su espada en alto con orgullo y cansancio; con la cabeza en alto por haber sobrepasado pruebas académicas, económicas, sociales, relacionales, que día a día y noche a noche tuvieron en su residencia.

Hoy con el brillo en sus ojos les recuerdo que no olviden el sufrimiento. Ni el propio ni el ajeno, pues ese es nuestro pan de cada día y el motor que nos impulsa a ser mejores. Mantengan la chispa inicial de ese día que decidieron estudiar medicina, reflejen de nuevo en sus ojos el brillo y el orgullo de los ojos de sus padres al

\footnotetext{
* Presidente del Consejo Superior de la Fundación Universitaria de Ciencias de la Salud, Bogotá DC. Colombia.
} 
enterarse de que ustedes querían ser médicos y asumanlo con fervor y pasión, que inmersos en el sufrimiento somos la esperanza. Brinden amor y alivio a sus pacientes, bienestar y cariño a sí mismos y a sus familias. Tienen en sus manos el instrumento privilegiado de la medicina para blandirlo sobre las condiciones que amenazan la calidad de vida de nuestra gente. Sin duda, el solo hecho de completar sus programas debería ser razón suficiente para celebrar y llenarse de orgullo. Pero sería descuidado en mi elogio hacia ustedes si no reconociéramos el apoyo irrestricto, el amor y la paciencia de aquellos que los han acompañado en este proceso, sus familias.

La Fundación Universitaria de Ciencias de la Salud, ha encontrado el camino para preservar la tradición y el prestigio que por tantos años la Sociedad de Cirugía de Bogotá ha impreso en las generaciones de médicos colombianos. Nuestra escuela de posgrados no solo es abundante en campos de la especialización médica, sino que mantiene, fiel a su costumbre, los más altos estándares de calidad y excelencia académica.

Hoy en medio de esta ceremonia hemos querido rendir un merecido homenaje a uno de nuestros maestros más queridos y digno exponente de la medicina interna y la cardiología colombiana, Maestro de Maestros para cientos de colegas que hemos tenido la fortuna de haber sido sus alumnos. Un ejemplo como profesional, como docente, esposo, padre, abuelo, amigo y como ser humano, un colega que ha dado lustre a nuestra Sociedad de Cirugía de Bogotá-Hospital de San José, al Departamento Médico, al Servicio de Medicina Interna y a la Fundación Universitaria de Ciencias de la Salud y su Facultad de Medicina. Queridos amigos, graduandos, colegas y familiares aquí presentes: es un honor para mí presentar al Profesor Doctor José Ignacio Hernández, médico de la Universidad Nacional de Colombia, se especializó en medicina interna y cardiología en 1.967 , fue catedrático de la Universidad Javeriana hasta 1.970 y desde entonces de la Facultad de Medicina de la Universidad del Rosario. En 1998 es profesor Titular de la especialidad en la FUCS, ocupó la jefatura de la División Médica de nuestra institución universitaria y jefe del servicio de medicina interna del Hospital de San José. Ingresó a la Sociedad de Cirugía de Bo- gotá como asociado en 1.976, ascendió a miembro de número en 1.981 y en la actualidad es Honorario. Ha ocupado posiciones directivas en el Hospital de San José. El Profesor Hernández pertenece a numerosas sociedades científicas y profesionales y es autor de un sinnúmero de artículos científicos y coautor de textos de la especialidad.

En reconocimiento a toda una vida dedicada a la formación de médicos y de especialistas en medicina interna y cardiología, queremos exaltar su labor y los innumerables logros profesionales y académicos, otorgándole la categoría de Profesor Emérito de la Fundación Universitaria de Ciencias de la Salud, Facultad de Medicina, escuela de Posgrados, acorde con el artículo 70 del capítulo XIII del estatuto docente, que trata de los honores y distinciones que otorga nuestra institución universitaria y que dice:" la distinción de Profesor Emérito podrá concederse al docente que por más de veinte años haya ejercido su cargo y que después de retirarse en la categoría de Profesor Titular sea considerado merecedor de este distinción por haberse destacado en la enseñanza, en la investigación, en la administración académica o por haber prestado servicios notables a la institución." Lo que por unanimidad ha sido reconocido por el Consejo de la Facultad de Medicina y el Consejo Superior de la FUCS por solicitud del señor Rector Sergio Parra Duarte.

Profesor José Ignacio Hernández, querido profesor Chepe Hernández como lo conocemos con cariño, quiero en nombre de la Sociedad de Cirugía de Bogotá-Hospital de San José y de su Junta Directiva, del Consejo Superior de la FUCS y de toda la comunidad académica y hospitalaria agradecerle por todos sus aportes, dedicación, paciencia, entrega y compromiso con nuestras instituciones durante todo este tiempo y esperamos contar con sus enseñanzas y experiencia por muchos años más. Solicito de los queridos graduandos y de todos ustedes un merecido y caluroso aplauso para el Profesor Doctor José Ignacio Hernández Cruz.

La Fundación está dirigiendo sus esfuerzos hacia el fortalecimiento estratégico y como parte fundamental, hemos considerado vital renovar los posgrados, como lo exigen las tendencias mundiales; crear nuevos 
programas de pregrado y visualizarnos en un futuro muy cercano como una universidad acreditada, para lo cual estamos trabajando con compromiso y dedicación, buscando siempre los mejores estándares de calidad en todos nuestros programas. Ya hemos recibido reconocimiento y acreditación de alta calidad en las facultades de medicina, enfermería e instrumentación quirúrgica, contamos con nuestros centros de práctica propios, dos hospitales acreditados y creciendo en alianza con otras instituciones hospitalarias y de educación superior, buscando un proceso de mejoramiento institucional continuo como política del Consejo Superior y de gestión en cabeza del señor Rector Doctor Sergio Parra Duarte y todo su equipo de colaboradores, cumpliendo con nuestra oferta de valor y como compromiso con nuestros estudiantes, docentes, la comunidad académica y el país.
Queridos graduandos, colegas, el grado que ustedes obtienen hoy, adquiere un significado especial si entendemos lo importante que es ofrecerle al país médicos especialistas con una visión multidisciplinaria, que tejen su conocimiento sobre una base muy amplia en ideas, principios y métodos, sin descuidar el factor humano que los hace hombres y mujeres dignos de ejercer la medicina. Quiero manifestarles mi admiración y aprecio por la meta que atraviesan y en representación de la comunidad académica felicitarlos y desearles éxitos en esta nueva etapa de sus vidas. Invitarlos a seguir en contacto con su alma mater y llevar siempre en alto el nombre de las instituciones del grupo empresarial de San José, que han contribuido en su formación profesional y personal. Un abrazo y que Dios los bendiga. 